\title{
A ESCASSEZ HÍDRICA EM ÁREAS RURAIS DO TERRITÓRIO DO CBH JQ3 - VALE DO JEQUITINHONHA - MG
}

\section{ARTIGO DE REVISÃO}

MARQUES, Wanderson Oliveira ${ }^{1}$

PRATES, William Santos ${ }^{2}$

GONÇALVES, Rubens Gomes ${ }^{3}$

MARQUES, Wanderson Oliveira. PRATES, William Santos. GONÇALVES, Rubens Gomes. A escassez hídrica em áreas rurais do território do CBH JQ3 - Vale do Jequitinhonha - MG. Revista Científica Multidisciplinar Núcleo do Conhecimento. Ano 05, Ed. 10, Vol. 01, pp. 101-109. Outubro de 2020. ISSN: 2448-0959, Link de acesso: https://www.nucleodoconhecimento.com.br/meio-ambiente/escassez-hidrica

\section{RESUMO}

Essa revisão bibliográfica teve como objetivo buscar dados relevantes sobre a situação hídrica do Vale do Jequitinhonha, em especial a parte média e baixa da bacia; e entender como a população rural é afetada pela falta desse recurso tão importante para a vida que é a água. Para atingir esse objetivo foi usada a metodologia de revisão da literatura existente sobre o tema, usando os estudos realizados por GONTINJO (2001), RIBEIRO; GALIZONI (2003), GALIZONI et al. (2008) e RIBEIRO et al. (2016) entre outros autores, procurando sempre estabelecer uma conexão entre o problema

${ }^{1}$ Mestrando em Conservação da Biodiversidade e Desenvolvimento Sustentável ESCAS/IPÊ, Especialista em Geografia e Meio Ambiente - Faculdade Única de Ipatinga, Graduado em Gestão Ambiental - Universidade Paulista/UNIP, Graduando em Ciências Biológicas - IFNMG.

2 Graduando em Ciências Biológicas.

${ }^{3}$ Graduando em Ciências Biológicas. 
da escassez hídrica e sua fonte causadora, bem como o modo que a população camponesa tem lidado com a problemática. Foi concluído que a região vem enfrentando problemas com a falta de água, mas que o problema se agravou a partir da década de 70 do século passado quando o governo resolveu substituir a formação vegetal natural por grandes monoculturas de eucalipto visando desenvolver economicamente a região e abastecer as indústrias siderúrgicas e de papel e celulose. Fica ainda concluído que a população rural ficou de fora da gestão participativa da água implantada pela Lei 9.433/1997. Apesar de todos os problemas ainda se pode concluir que existem ações de recuperação do meio ambiente voltada a preservar os recursos hídricos, desenvolvidas tanto pela comunidade quanto pelo governo.

Palavras-chave: Água, recursos hídricos, escassez, seca, Vale do Jequitinhonha.

\section{INTRODUÇÃO}

Este trabalho buscou fazer um apanhado da situação hídrica do Vale do Jequitinhonha, em especial a sua porção média e baixa, a qual o território faz parte do Comitê de Bacias Hidrográficas - CBH JQ3, bem como analisar as consequências dessa escassez no modo de vida da população rural daquela região. Para atingir o resultado esse trabalho buscou investigar se há escassez hídrica no Vale do Jequitinhonha; e, como essa falta d'água afeta os costumes e a vida da população rural ali residente.

Desde que o homem deixou o campo e se agrupou em núcleos chamados cidades, criou condições para viver mais e melhor, não só nesses núcleos como também no próprio campo. Mas o preço desse avanço foi a degradação de habitats para suprir necessidades e vontades da população humana, mais evidente a partir da revolução industrial. (MEADOWS et al., 1978).

Essa degradação tem gerado efeitos diferentes em lugares distintos quando se trata de perceber os efeitos da devastação ambiental. Os reflexos da ação humana são percebidos de forma única pelas populações tradicionais e rurais do Vale do Jequitinhonha região nordeste do Estado de Minas Gerais. (RIBEIRO; GALIZONI, 
2003; PEREIRA; ALMEIDA e LEITE, 2003; GALIZONI et al., 2008; RODRIGUES; THÉ, 2014; RIBEIRO et al., 2016).

A região foi dividida administrativamente em três microrregiões, essa divisão também serve para nortear as políticas públicas de gestão de Bacias Hidrográficas, nesse sentido a bacia ficou assim dividida:

CBH JQ1, se estende desde a nascente até o encontro do Rio Jequitinhonha com o Rio Vacaria, um de seus principais afluentes que fica logo abaixo da represa de Irapé, compõe a rede de drenagem dos afluentes mineiros do Alto Rio Jequitinhonha. (IGAM, 2020).

CBH JQ2, foi criado para gerir a bacia do Rio Araçuaí, principal afluente do Rio Jequitinhonha, e sua maior sub bacia. (IGAM, 2020).

CBH JQ3, esse é o comitê que compõe a área de estudo desta revisão bibliográfica. Possui uma área de drenagem de $29.617 \mathrm{~km}^{2}$ - 45,04\% do território da bacia do Rio Jequitinhonha, conta com uma população de 380.341 habitantes sendo um terço destes vivendo em área rural. (IBGE, 2010; IGAM, 2020). 
Figura 1: Mapa da área de drenagem do CBH JQ3.

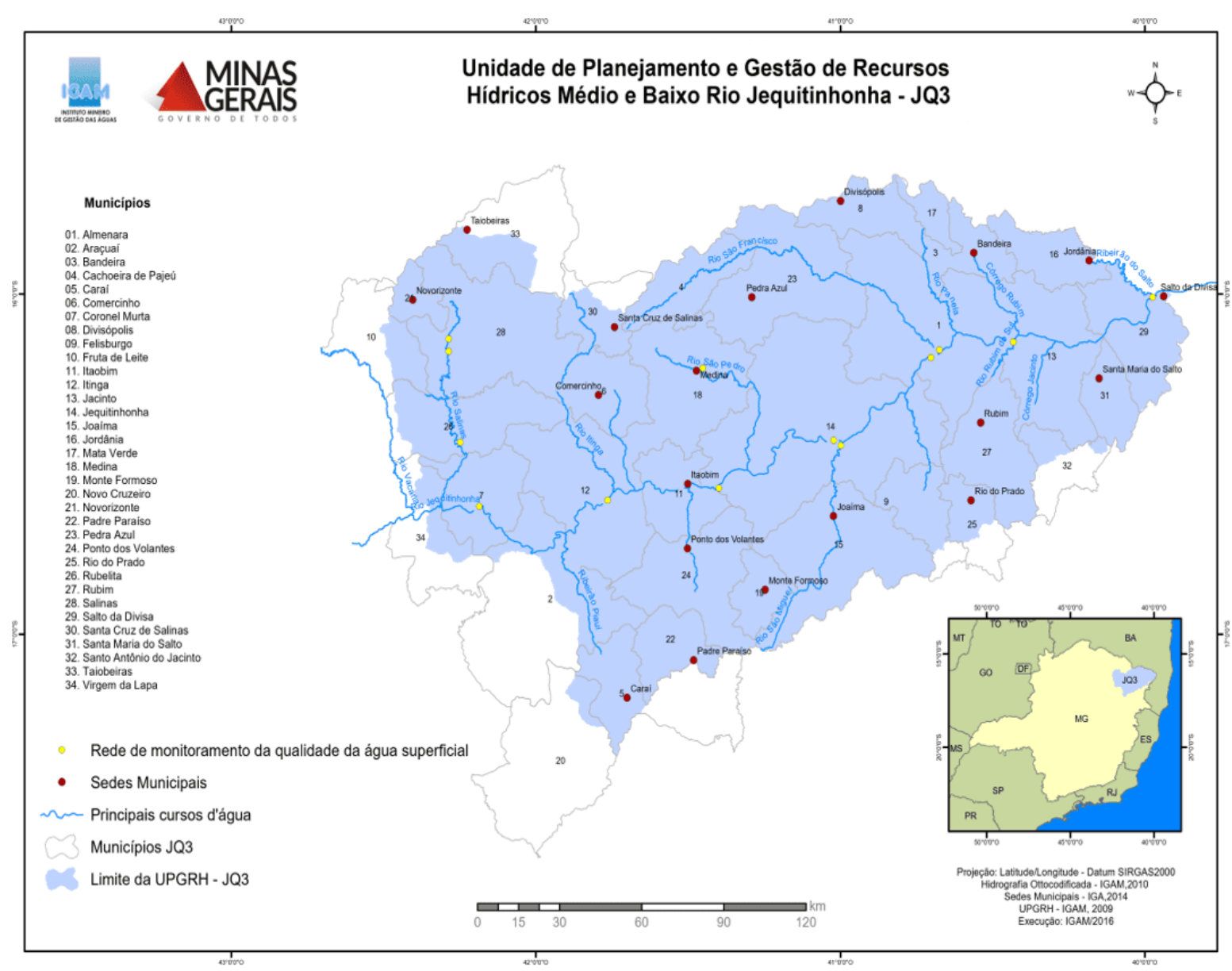

Fonte IGAM (2016)

O território é marcado pelo baixo Índice de Desenvolvimento Humano - IDH, pela sazonalidade das precipitações e pelo aspecto climático semiárido; além de passar por períodos frequentes de seca onde os índices pluviométricos caem ao extremo mesmo durante o período que deveria ser chuvoso. (GONTINJO, 2001; SOUZA, 2003; FILHO; SILVA e SILVA, 2009; RIBEIRO e GALIZONI, 2003).

Assim o objetivo desse trabalho foi averiguar a existência de escassez hídrica na região do Vale do Jequitinhonha, nordeste de Minas Gerais, em especial a porção média e baixa da bacia, área de atuação do CBH JQ3.

Para atingir os objetivos a metodologia utilizada foi a revisão da bibliografia, pesquisando artigos, monografias, dissertações e teses publicados em periódicos 
conceituados, bem como nos repositórios de universidades de renome. Foi usada como ferramenta de busca o Google Escolar.

\section{DESENVOLVIMENTO}

O modelo adotado pelos governos local e federal para alavancar economicamente a região, desde a década de setenta, tem causado transtornos à população camponesa, bem como danos ao meio ambiente local. Para os governos, o modelo desenvolvimentista escolhido passava pelo desmatamento das chapadas que compõe a região, trocando a cobertura florestal nativa por monocultura de eucalipto. (GONTINJO, 2001; RIBEIRO e GALIZONI, 2003; PEREIRA; ALMEIRA e LEITE, 2003; GALIZONI et al., 2008; RIBEIRO et al., 2016).

Ironicamente os projetos fomentados pelo programa de desenvolvimento da região era denominado reflorestamento. A ironia está em desmatar (desflorestar) determinada área para depois reflorestá-la com espécies exóticas. (GONTINJO, 2001; RIBEIRO e GALIZONI, 2003; GALIZONI et al, 2008).

Essas ações foram realizadas e fomentadas pelo governo na parte alta e média do vale e quando somadas ao aspecto climático regional, aceleraram os processos erosivos naturais da bacia hidrográfica como um todo, impactando diretamente no modo de viver e se relacionar com o ambiente, não só das comunidades e povos tradicionais, mas também de toda a população camponesa. (RIBEIRO e GALIZONI, 2003; GALIZONI et al, 2008).

A partir da percepção de que a água era finita e estava diminuindo devido à poluição dos mananciais e aumento da demanda, a escassez hídrica se torna realidade, não apenas na região, mas também no cenário mundial. Quando isso ocorre o mundo passa a se preocupar cada vez mais em regular o uso e calcular o valor pecuniário desse recurso natural que passa a ser tratado como ativo econômico. (GALIZONI et al., 2008; RIBEIRO et al., 2016). 
Nesse sentido, buscando uma melhor participação social na administração e distribuição dos recursos hídricos, entendidos como bem público, cria-se os comitês gestores das bacias hidrográficas, o que é um grande avanço na proteção das águas, no entanto, essa gestão participativa acaba deixando de fora uma parcela significativa da sociedade, justamente a que mais sofre com a falta e escassez de água, as comunidades tradicionais e camponesas incluindo aí as do Vale do Jequitinhonha. (GALIZONI, 2003; GALIZONI et al., 2008; RIBEIRO et al., 2016).

Os camponeses dessa região olham para a água de forma diferente, para eles a água se divide e se torna plural, passando a existir a água das nascentes, que servem para beber e satisfazer as necessidades mais básicas, por se tratar de uma água pura e as águas dos córregos lagos e rios, que são consideradas sujas ou contaminadas sendo usadas apenas na falta total de outra fonte. (RIBEIRO e GALIZONI, 2003).

Essa dependência das nascentes, somadas às más práticas ambientais adotadas na região ao longo de muito tempo, tem contribuído para restringir cada vez mais o acesso à água pela população rural local, o que levou as comunidades do alto e médio vale a criarem seu próprio sistema de gestão, bem simples e baseado em hierarquia de uso do recurso; quando tem em abundancia - período das chuvas - é permitido todos os usos, já no período de estiagem passa-se a priorizar o uso doméstico, isso impacta diretamente a renda e a disponibilidade de alimentos para essas famílias. (RIBEIRO e GALIZONI, 2003).

A má gestão dos recursos, em especial os hídricos, juntamente com a característica climática, com poucas chuvas e que tem passado por períodos cíclicos de estiagens, o que contribui para a diminuir a disponibilidade hídrica regional, chegando a afetar atém mesmo algumas cidades. (DINIZ et al., 2001).

Com a diminuição das fontes de água para abastecimento da população rural, (RODRIGUES; THÉ, 2014; GALIZONI et al., 2008; RIBEIRO et al., 2016; RIBEIRO; GALIZONI, 2003; PEREIRA; ALMEIDA e LEITE, 2003; DINIZ, et al., 2001), diante da ineficiência dos comitês em gerir igualitariamente os recursos hídricos, (RIBEIRO e GALIZONI, 2003), com a poluição promovida pelos garimpos e com o impacto que 
esse cenário pode acarretar no abastecimento e sobrevivência das cidades; surgiram aos poucos iniciativas populares, governamentais e da sociedade civil organizada para tentar frear o avanço da degradação ambiental que assola a região. Entre essas iniciativas estão ações de proteção de nascentes criadas pela própria comunidade; 0 programa de fomento do Instituto Estadual de Florestas - IEF, o Projeto de Combate à Pobreza Rural - PCPR da EMATER-MG e os projetos de moradores locais que visam revitalizar e proteger nascentes e um extenso programa de Educação Ambiental, de forma continuada. (ALCÂNTARA FILHO; SILVA; SILVA, 2009; PEREIRA, 2016).

\section{CONCLUSÃO}

Diante dos resultados da pesquisa bibliográfica apresentada, é possível perceber que a região do Vale do Jequitinhonha, por ser de clima semiárido, já sofria naturalmente com escassez hídrica; mas esse problema foi agravado pela ação do homem ao longo dos anos.

É importante notar que há uma cronologia de surgimento dos problemas, que se iniciam na década de 70, com a ideia governamental de fomentar o desmatamento nas chapadas, que compõe aquela região, visando implantar ali um polo de produção silvicultural a base da monocultura de eucalipto. A partir desse momento os problemas com a falta de água para todos começam a se agravar.

Cabe ainda salientar que a ação governamental foi iniciada com o pretexto de desenvolver economicamente a região, uma vez que a chegada de grandes empresas reflorestadoras iria injetar dinheiro e gerar empregos em uma região que vinha sendo descrita como muito pobre, onde as taxas e indicadores de desenvolvimento humano eram baixíssimos. No entanto, por não se preocuparem em planejar essa medida desenvolvimentista, visando ouvir as necessidades da população local bem como promover o desenvolvimento de forma sustentável a ação acabou agravando um problema local que já existia devido as peculiaridades climáticas. 
Ainda é preciso ponderar que a gestão participativa dos recursos hídricos, novidade implementada pela nova lei das águas (Lei no 9.433/1997), apesar de ser muito importante e um grande avanço no campo de preservação do meio ambiente, não conseguiu de imediato incluir as comunidades rurais e tradicionais e dar voz a estes nos debates, bem como chance de ocuparem cadeiras nos Comitês de Bacias, relegando essas comunidades à margem das decisões que impactariam suas vidas de forma bastante contundente.

Não obstante a essa nova realidade, as comunidades se valendo da forma tradicional de viver, conseguem criar um sistema próprio, adaptado as necessidades locais, de gestão dos recursos hídricos. Tal sistema se baseia na hierarquia do uso da água, tendo como prioridade o abastecimento humano, que reflete o uso para beber, tomar banho e cozinhar; e só depois, se sobrar água a mesma poderá ser usada para irrigação, dessedentação animal entre outros usos. É preciso salientar que essa forma de gerir o recurso, apesar de eficiente, pode ser geradora de conflitos rurais pelo uso da água.

Outro importante fator que é possível extrair dessa pesquisa é o surgimento de ações voltadas a tentar reverter o quadro ambiental delicado que a região chegou. $O$ fato de alguns dessas atitudes terem surgido a partir das comunidades é um bom sinal de duração ao longo do tempo, o que pode aumentar as chances de a ação alcançar sucesso.

Por fim a conclusão é que o Vale do Jequitinhonha apesar de ser uma região bastante pobre e castigada pela falta de água em algumas comunidades da zona rural, tem um grande potencial de se desenvolver de forma mais justa e eficiente no futuro, bastando para isso as ações elencadas ao logo dessa revisão terem continuidade, bem como um olhar mais cuidadoso por parte dos vários níveis de governo para as questões sérias de degradação que o local possui. 


\section{REFERÊNCIAS}

ALCÂNTARA FILHO, José Luiz; DA SILVA, Márcio Gomes; SILVA, Sandro Pereira. A abordagem Territorial do Desenvolvimento rural: Uma análise a partir do território rural Baixo Jequitinhonha. Perspectivas em Políticas Públicas, Belo Horizonte, v. 2, n. 3, p. 24-44, 2009. Disponível em http://200.198.28.135/index.php/revistappp/article/view/961/681. Acesso em: 13 maio 2020.

ASSIS, TRP; MELO, APG; SILVESTRE, L. H. Água, produção e tecnologias: uma análise da relação entre populações rurais e ambiente no alto JequitinhonhaMG. ENCONTRO NACIONAL DE ESTUDOS POPULACIONAIS, ABEP, v. 14, 2004.

DINIZ, H. N. et al. Geologia, climatologia e hidrologia da Bacia do Rio Araçuaí, Estado de Minas Gerais-Brasil. Encontro de Geógrafos da América Latina, v. 8, 2001.

GALIZONI, Flávia Maria et al. Água e aglomeração espacial da população rural do alto Jequitinhonha, Minas Gerais. Anais, p. 1-18, 2016.

GONTIJO, Bernardo Machado Gontijo. Implicações do plantio generalizado de eucaliptus no empobrecimento social e da biodiversidade do alto/médio Jequitinhonha-MG. Boletim Paulista de Geografia, n. 77, p. 57-78, 2001.

IBGE. Censo 2010. Disponível em: https://censo2010.ibge.gov.br/. Acesso em: 19 maio 2020.

IGAM. Comitês Estaduais - MG. 2020. Disponível em: http://comites.igam.mg.gov.br/comites-estaduais-mg/. Acesso em: 19 maio 2020.

MEADOWS, Denis. Limites do Crescimento: um relatório para o projeto do Clube de Roma sobre o dilema da humanidade. Coleção Debates. São Paulo, Perspectivas, 1978. 
PEREIRA, Anete Marília; DE ALMEIDA, Maria Ivete; LEITE, Marcos Esdras. Considerações acerca da degradação ambiental no município de Araçuaí, no Vale do Jequitinhonha. Unimontes Científica, v. 5, n. 2, p. 85-92, 2003.

RIBEIRO, Eduardo Magalhães; GALIZONI, Flávia Maria. Água, população rural e políticas de gestão: o caso do vale do Jequitinhonha, Minas Gerais. Ambiente \& sociedade, v. 5, n. 2, p. 129-146, 2003.

RIBEIRO, Eduardo Magalhães et al. Práticas, preceitos e problemas associados à escassez da água no Vale do Jequitinhonha, Minas Gerais. Anais, 2016.

SILVEIRA, Carlos Jose Andrade. Proposta de indicadores para a avaliação de projetos de restauração de ecossistemas no Alto Jequitinhonha. 2012.

Enviado: Setembro, 2020.

Aprovado: Outubro, 2020. 